\title{
Interactive comment on "Dynamic upscaling of decomposition kinetics for carbon cycling models” by Arjun Chakrawal et al.
}

Arjun Chakrawal et al.

arjun.chakrawal@natgeo.su.se

Received and published: 25 September 2019

The comment was uploaded in the form of a supplement:

https://www.geosci-model-dev-discuss.net/gmd-2019-133/gmd-2019-133-AC2-

supplement.pdf

Interactive comment on Geosci. Model Dev. Discuss., https://doi.org/10.5194/gmd-2019-133, 2019. 